\title{
Determinants of Skilled Birth Attendance in the Northern Parts of Ghana
}

\author{
Kwamena Sekyi Dickson ${ }^{1}$ and Hubert Amu² \\ ${ }^{1}$ Department of Population and Health, College of Humanities and Legal Studies, University of Cape Coast, Cape Coast, Ghana \\ ${ }^{2}$ Department of Population and Behavioural Sciences, School of Public Health, University of Health and Allied Sciences, Hohoe, Ghana
}

Correspondence should be addressed to Kwamena Sekyi Dickson; nadicx@gmail.com

Received 29 November 2016; Revised 10 July 2017; Accepted 6 November 2017; Published 26 November 2017

Academic Editor: Jennifer L. Freeman

Copyright ( 2017 Kwamena Sekyi Dickson and Hubert Amu. This is an open access article distributed under the Creative Commons Attribution License, which permits unrestricted use, distribution, and reproduction in any medium, provided the original work is properly cited.

\begin{abstract}
Background. An integral part of the Sustainable Development Goal three is to ensure universal access to sexual and reproductive healthcare services which include skilled delivery by the year 2030. We examined the determinants of skilled delivery among women in the Northern part of Ghana. Methods. The paper made use of data from the Demographic and Health Survey. Women from the Northern part of Ghana were included in the analysis. Bivariate descriptive analyses coupled with binary logistic regression estimation technique were used to analyse the data. Results. Region of residence, age, household wealth, education, distance to a health facility, religion, parity, partner's education, and getting money for treatment were identified as the determinants of skilled delivery. While the probability of having a skilled delivery was higher in the Upper East Region, it was lower in the Northern and Upper West Regions compared to the Brong Ahafo Region. Conclusion. Our findings call for more attention from the Ghana Health Service and the Ministry of Health in addressing the skilled delivery gaps among women particularly in the Northern and Upper West Regions in ensuring attainment of the Sustainable Development Goal target related to reproductive health care accessibility for all by the year 2030 .
\end{abstract}

\section{Introduction}

Access to skilled care during delivery is crucial to reducing maternal mortality [1]. This is based on the premise that, worldwide, about 830 women die every day due to complications resulting from pregnancy and childbirth [2]. Almost all of these deaths occur in low-resource settings and are preventable [2]. Out of the 830 deaths recorded, for instance, 550 occurred in sub-Saharan Africa and 180 in southern Asia, compared to five in developed countries [2]. The implication is that the risk of a woman dying due to obstetric causes during her lifetime in a developing country is about 33 times higher than for a woman living in a developed country [2]. Many studies have, for instance, indicated that more than three-fourths of maternal deaths recorded in developing countries are associated with direct obstetric causes such as haemorrhage, sepsis, abortion, hypertensive diseases of pregnancy, and ruptured uterus, and that over $77 \%$ of such deaths occur during childbirth or soon after delivery (within 24 hours) [2-4].
A major reason for the high maternal deaths in developing countries is the low utilization of skilled delivery services provided by skilled birth attendants (SBAs) for the majority of the women [5]. A skilled birth attendant is defined as "an accredited health professional - such as a midwife, doctor or nurse - who has been educated and trained to proficiency in the skills needed to manage normal (uncomplicated) pregnancies, childbirth, and the immediate postnatal period, and in the identification, management and referral of complications in women and newborns" [6].

The issue of maternal utilization of skilled delivery services is based on a conceptual framework for health-seeking behavior by Andersen and Newman [7]. The tenets of the model are predisposing, need, and enabling factors which influence the utilization of healthcare services. Predisposing factors include religion, sex, education, social networks, age, previous experience with illness, attitudes, and values [8]. Enabling factors are described as being external to the individual, but important in influencing his/her decisions 
concerning the use of healthcare services. They include income, availability of health facilities and personnel, waiting time at health facilities, quality and extent of social relationships, and health [9]. The need factors according to Andersen and Newman [7] refer to perceptions of the seriousness of a disease or health condition and include people's view of their own general health and functional state as well as the availability of help for care and support [7]. Existing predisposing factors according to the model combined with enabling and need factors to influence a person's utilization of healthcare facilities and services $[8,9]$.

Studies have shown that maternal and newborn mortalities are usually low when higher proportions of deliveries are attended by SBAs [10-12]. SBAs play significant roles in decreasing maternal mortality, as they offer timely obstetric care for life-threatening complications [13]. The low levels of utilization of skilled delivery services which lead to high rates of maternal mortality have been attributed to various factors including access to health facilities, health worker attitude towards women during delivery, cultural issues, maternal age, and parity $[14,15]$. Primiparous women are, for instance, more likely to access skilled delivery while multiparous women also opt for unskilled support during delivery due to the perception of being experienced [15]. Transportation factors influencing the low utilization of skilled birth attendance also include poor road network, lack of a vehicle, and the high cost of transport [16].

In 2015, the Sustainable Development Goals (SDGs) were constituted to replace the Millennium Development Goals to which Ghana was a signatory $[17,18]$. The Millennium Development Goals were eight goals which sought to propel the socioeconomic development of developing countries from 2000 to 2015 [19]. At the end of 2015, however, most of the developing countries, including Ghana, were unable to meet their MDG targets including those related to maternal health (MDG 5) [17-19]. Seventeen new SDGs were, therefore, developed to replace the MDGs. The SDG Goal three seeks to ensure healthy lives and promote well-being for all of all ages by the year $2030[18,20]$. An integral part of this goal is to ensure universal access to sexual and reproductive healthcare services which include skilled delivery services [20]. To achieve this target, an understanding of the skilled delivery service utilization among women of all sociodemographic and economic backgrounds is imperative.

Ghana is usually categorized into a north-south divide based on the level of development and also for comparison [21-23]. The Greater Accra, Central, Volta, Western, Ashanti, and Eastern regions constitute the southern part while the Brong Ahafo, Northern, Upper East, and Upper West regions form the Northern part. Several studies have in the past found utilization of health care services including skilled delivery as being higher in the southern part of the country than in the Northern part [24-27]. In this regard, Abor et al. [28] for instance argued that geographical location is an important factor which influences the utilization of maternal health services. Also, Addai [29] in a study on the determinants of use of maternal-child health services in rural Ghana posited that living in the Central and Western regions (both located in the southern part of the country) increased the probability of consulting a physician for antenatal care services compared to living in the Northern part of the country. Addai [29] also noted that, compared to the Northern parts of Ghana, women residing in rural areas of western and central regions were two times more likely to see a physician for prenatal care compared with women in the Northern part. This is largely attributable to the adequacy and ease of access to health personnel and facilities among women living in rural areas of the southern parts of the country compared to those in the Northern part of the country [29-32]. Our study contributes to the body of knowledge available on skilled delivery by examining the determinants of skilled delivery in the Northern part of Ghana and making useful recommendations for policy and practice.

\section{Materials and Methods}

The study made use of data from the individual recode file of the Ghana Demographic and Health Survey (GDHS) 2014. Ghana Demographic and Health Survey is a nationwide survey which covers all the ten regions in Ghana and is designed and conducted every five years. The GDHS focuses on child and maternal health and is designed to provide adequate data to monitor the population and health situation in Ghana. GDHS gathers information on antenatal care, delivery care and postnatal care, fertility contraceptive use, child health, family planning, and much more.

The survey was carried out by the Ghana Statistical Service and the Ghana Health Service with technical support from ICF International through the MEASURE DHS program. In the 2014 version 9,396 women between the ages 15 and 49 from 12,831 households covering 427 clusters throughout Ghana were interviewed. It had a response rate of $97 \%$ [33]. For the purpose of this study, only women from the Northern part of Ghana who gave birth within five years prior to the survey were considered; sample of 1786 women was used. Permission to use the data set was given to us by MEASURE DHS following the assessment of a concept note. The dataset is available to the public (https://dhsprogram.com/).

Ten explanatory variables were used. These comprised maternal age, education, distance to health facility, ethnicity, parity (birth order), partner's education, getting money for treatment, religion, marital status, and household wealth. Maternal age was categorized into 15-19, 20-24, 25-29, 20-34, 35-39, 40-44, and 45-49. Education was classified into four categories: no education, primary education, secondary education, and higher education. Marital status was recoded as single (never married, widowed, and divorced), married, and cohabitating (living together). Distance to a health facility was coded as a big problem and not a big problem. Household wealth was created from wealth status in DHS dataset, which is an accumulation using factor analysis of various household belongings including agricultural land, car, refrigerator, materials used in constructing housing, bicycle, television, type of household cooking fuel, and radio [33]. Household wealth status was categorized as poorest, poorer, middle, richer, and richest. Parity (birth order) was 
categorized as zero birth, one birth, two births, three births, and four births or more. Partner's education was classified into four categories: no education, primary education, secondary education, and higher education. Getting money for treatment was captured as big problem and not a big problem.

\section{Analysis}

Since our interest was to examine the probability of utilizing skilled delivery services, the outcome variable employed for this study was assisted skilled delivery. This was derived from the question "who assisted with the delivery?" Responses of those who received assistance from a doctor, nurse/midwife, and community health officer/nurse were captioned as assisted skilled delivery. The outcome variable was coded as 1 = "Yes" and $0=$ "No" since it was a dichotomous variable. A logit model was employed to show how the explanatory variables correlated with the outcome variable. Specifically, the binary logistic regression was employed since it allows the predictions of a mixture of continuous and categorical variables. Binary logistic regression is based on the assumption that the dependent variable should be a dichotomous variable and the data should not contain outliers. The formulae behind the binary logistic regression are given as follows.

Let $Y$ be a dichotomous variable which is defined as

$$
\begin{aligned}
& Y=\frac{1 \text { for users of skilled birth attendants }}{0 \text { for non-users of skilled birth attendants }} \\
& p=\operatorname{Pr}\left(Y=1 \mid X_{1}, \ldots, X_{k}\right) \\
& p=\frac{1}{1+\exp \left[-\left(\beta_{0}+\beta_{1} X_{1}+\beta_{2} X_{2}+\cdots+\beta_{k} X_{k}\right)\right]}, \\
& \widehat{p}=\frac{1}{1+\exp \left[-\left(\widehat{\beta}_{0}+\widehat{\beta}_{1} X_{1}+\widehat{\beta}_{2} X_{2}+\cdots+\widehat{\beta}_{k} X_{k}\right)\right]} .
\end{aligned}
$$

Note. With no predictors, $\widehat{p}=\sum_{i=1}^{n} Y_{i} / n=\bar{Y}$.

The model was employed to show how the explanatory variables correlated with the outcome variable. Two models were used for the binary logistic regression. Model 1 was a bivariate analysis of each explanatory variable with the outcome variable, to check the effects of the individual explanatory variables on the outcome variable. Model 2 was a multivariate analysis of all the explanatory variables with the outcome variables.

Survey weights, which are typical of nationally representative studies, were factored into both inferential and descriptive analyses conducted. The weights helped to offset the challenges of under- and oversampling usually associated with national surveys. All analyses were conducted with STATA, version 13 . The level of significance used in the study was at $95 \%$ or $<0.05$.

\section{Results}

Table 1 presents the utilization of skilled birth attendants based on sociodemographic characteristics. Nine of the explanatory variables showed significant associations with the dependent variable: age, household wealth, education, region, distance to a health facility, religion, parity, partner's education, and getting money for treatment. It was observed that women aged 25-29 years had the highest proportion of skilled delivery (25\%). Utilization of skilled delivery at birth declined with increasing household wealth.

Women with no formal education had the highest proportion of skilled delivery (59.8\%) while those with the highest form of education had the least (1.8\%). Regarding region, women from the Northern Region had the highest proportion of skilled deliveries (43.6\%) compared to women from the Upper West Region, who had the least (10\%). The Brong Ahafo and Upper East Regions also had proportions of $30.4 \%$ and $16 \%$, respectively. Women who did not consider distance to a health facility as a big problem had a higher proportion of skilled deliveries (63.1\%) compared to those who consider it a big problem (36.9\%). Christian women (49.5\%), women with four or more births $(50.3 \%)$, those whose partners had no education (53\%), those who considered getting money for treatment as a big problem (50.8\%), and married women (78.3\%) had the highest proportion of skilled deliveries in terms of religion, parity, partner's education, getting money for treatment, and marital status, respectively.

Table 2 presents results of the logistic regression analyses conducted for skilled delivery and the explanatory variables. For region, model 1 shows that the odds of accessing skilled delivery were higher for women in the Upper East Region $(\mathrm{OR}=1.74,95 \% \mathrm{CI}=1.08-2.21)$, while it was lower for those in the Northern $(\mathrm{OR}=0.20,95 \% \mathrm{CI}=0.15-0.26)$ and Upper West regions $(\mathrm{OR}=0.56,95 \% \mathrm{CI}=0.41-0.77)$ compared with women in the Brong Ahafo Region. We, however, observed that when the other variables were added, the odds of accessing skilled delivery increased for all three regions. This time, however, women in the Upper West Region were more likely to access skilled delivery $(\mathrm{AOR}=1.35,95 \% \mathrm{CI}=$ 0.91-2.01) compared with women in the Brong Ahafo Region.

Regarding household wealth, we realized in the bivariate analysis that women in the richer wealth quintile were 34.79 times more likely to utilize skilled delivery services than those in the poorest wealth quintile. This probability, however, declined when the other variables were added in model 2 $(\mathrm{AOR}=7.70,95 \% \mathrm{CI}=2.62-22.66)$. Women with primary and secondary education were more likely to utilize skilled delivery services than those with no formal education. In both models, however, women with primary and secondary education were more likely to utilize skilled delivery services than those with no education.

In both models, we observed that women in all the other age cohorts (ranging from 20 to 49), were less likely to utilize skilled delivery services compared to those aged 15-19 years. A similar finding was made regarding parity, where, in both models, women with two births, three births, and four or more births were all less likely than those with one birth to utilize skilled delivery services. While the relationship between parity and the dependent variable was found to be significant at $P<0.01$ and $P<0.001$ in the first model, it became insignificant upon addition of the other explanatory variables in the second model. 
TABLE 1: Background characteristics.

\begin{tabular}{|c|c|c|c|c|}
\hline Variable & Correlates & $n=1786$ & Percentage & $P$ value \\
\hline \multirow{7}{*}{ Age } & $15-19$ & 40 & 2.2 & \multirow{7}{*}{$<0.001$} \\
\hline & $20-24$ & 294 & 16.5 & \\
\hline & $25-29$ & 446 & 25.0 & \\
\hline & $30-34$ & 393 & 22.0 & \\
\hline & $35-39$ & 343 & 19.2 & \\
\hline & $40-44$ & 188 & 10.5 & \\
\hline & $45-49$ & 82 & 4.6 & \\
\hline \multirow{5}{*}{ Household wealth } & Poorest & 1043 & 58.4 & \multirow{5}{*}{$<0.001$} \\
\hline & Poorer & 341 & 19.1 & \\
\hline & Middle & 204 & 11.4 & \\
\hline & Richer & 138 & 7.7 & \\
\hline & Richest & 60 & 3.4 & \\
\hline \multirow{4}{*}{ Education } & No education & 1067 & 59.8 & \multirow{4}{*}{$<0.001$} \\
\hline & Primary & 288 & 16.1 & \\
\hline & Secondary & 399 & 22.3 & \\
\hline & Higher & 32 & 1.8 & \\
\hline \multirow{4}{*}{ Region } & Brong Ahafo & 543 & 30.4 & \multirow{4}{*}{$<0.001$} \\
\hline & Northern & 778 & 43.6 & \\
\hline & Upper East & 286 & 16.0 & \\
\hline & Upper West & 180 & 10.0 & \\
\hline \multirow{2}{*}{ Distance to health facility } & Big problem & 659 & 36.9 & \multirow{2}{*}{$<0.001$} \\
\hline & Not a big problem & 1127 & 63.1 & \\
\hline \multirow{4}{*}{ Religion } & Christianity & 883 & 49.5 & \multirow{4}{*}{$<0.001$} \\
\hline & Islam & 680 & 38.1 & \\
\hline & Traditional/spiritual & 143 & 8.0 & \\
\hline & No region & 80 & 4.4 & \\
\hline \multirow{4}{*}{ Parity } & One birth & 255 & 14.3 & \multirow{4}{*}{$<0.001$} \\
\hline & Two births & 318 & 17.8 & \\
\hline & Three births & 314 & 17.6 & \\
\hline & Four births or more & 899 & 50.3 & \\
\hline \multirow{4}{*}{ Partner's education } & No education & 947 & 53.0 & \multirow{4}{*}{$<0.001$} \\
\hline & Primary & 206 & 11.5 & \\
\hline & Secondary & 523 & 29.3 & \\
\hline & Higher & 110 & 6.2 & \\
\hline \multirow{2}{*}{ Getting money for treatment } & Big problem & 906 & 50.8 & \multirow{2}{*}{$<0.001$} \\
\hline & Not a big problem & 880 & 49.2 & \\
\hline \multirow{3}{*}{ Marital status } & Single & 95 & 5.4 & \multirow{3}{*}{0.63} \\
\hline & Married & 1399 & 78.3 & \\
\hline & Cohabiting & 292 & 16.3 & \\
\hline
\end{tabular}

In model 1, we observed that the probability of women utilizing skilled birth delivery increased with the level of education of their partners: primary $(\mathrm{OR}=2.97,95 \% \mathrm{CI}=$ $2.15-4.12)$, secondary $(\mathrm{OR}=4.62,95 \% \mathrm{CI}=3.55-6.01)$, and higher $(\mathrm{OR}=11.50,95 \% \mathrm{CI}=5.95-22.21)$. Even though a similar pattern was realized in model 2, we observed that both the level of significance and probability declined due to addition of the other explanatory variables: primary $(\mathrm{AOR}=$ 1.52 , 95\% CI $=1.04-2.22)$, secondary $(\mathrm{AOR}=1.62,95 \% \mathrm{CI}$ $=0.39-1.09)$, and higher $(\mathrm{AOR}=1.65,95 \% \mathrm{CI}=0.41-1.21)$. Women who lived in rural residences were less likely to utilize skilled delivery services as observed in both models 1 (OR $=0.19,95 \% \mathrm{CI}=0.14-0.25)$ and $2(\mathrm{AOR}=0.46,95 \% \mathrm{CI}=$ 0.31-0.67) (Table 2).

\section{Discussion}

We found that the probability of having a skilled delivery was higher in the Upper East Region than in the Brong Ahafo Region. The reverse, however, occurred where women in the Northern and Upper West Regions were less likely to access skilled assistance. This reflects the variations which exist 
TABLE 2: Binary logistic regression on skilled delivery among women in the Northern part of Ghana.

\begin{tabular}{|c|c|c|c|c|}
\hline Explanatory variable & $\begin{array}{l}\text { Model } 1 \\
\text { OR }\end{array}$ & $95 \%$ confidence interval & $\begin{array}{c}\text { Model } 2 \\
\text { AOR }\end{array}$ & 95\% confidence interval \\
\hline \multicolumn{5}{|l|}{ Region } \\
\hline Brong Ahafo & Ref & Ref & Ref & Ref \\
\hline Northern & $0.20^{* * *}$ & $0.15-0.26$ & $0.48^{* * *}$ & $0.33-0.69$ \\
\hline Upper East & $1.30^{*}$ & $1.08-2.21$ & $3.02^{* * *}$ & $1.96-4.66$ \\
\hline Upper West & $0.56^{* * *}$ & $0.41-0.77$ & 1.35 & $0.91-2.01$ \\
\hline \multicolumn{5}{|l|}{ Household wealth } \\
\hline Poorest & Ref & Ref & Ref & Ref \\
\hline Poorer & $2.11^{* * *}$ & $1.61-2.77$ & 1.38 & $0.99-1.92$ \\
\hline Middle & $5.71^{* * *}$ & $3.74-8.72$ & $2.11^{* *}$ & $1.25-3.60$ \\
\hline Richer & $34.79^{* * *}$ & $12.8-94.56$ & $7.70^{* * *}$ & $2.62-22.66$ \\
\hline Richest & 1 & 1 & 1 & 1 \\
\hline \multicolumn{5}{|l|}{ Education } \\
\hline No education & Ref & Ref & Ref & Ref \\
\hline Primary & $3.71^{* * *}$ & $2.75-5.01$ & $1.75^{* *}$ & $1.22-2.50$ \\
\hline Secondary & $6.27^{* * *}$ & $4.59-8.57$ & $1.79^{* *}$ & $1.20-2.66$ \\
\hline Higher & 1 & 1 & 1 & 1 \\
\hline \multicolumn{5}{|l|}{ Age } \\
\hline $15-19$ & Ref & Ref & Ref & Ref \\
\hline $20-24$ & 0.54 & $0.23-1.28$ & 0.67 & $0.25-1.82$ \\
\hline $25-29$ & 0.45 & $0.20-1.05$ & 0.59 & $0.21-1.61$ \\
\hline $30-34$ & $0.42^{*}$ & $0.18-0.97$ & 0.59 & $0.21-1.68$ \\
\hline $35-39$ & $0.38^{*}$ & $0.16-0.89$ & 0.58 & $0.20-1.69$ \\
\hline $40-44$ & $0.38^{*}$ & $0.15-0.91$ & 0.68 & $0.23-2.04$ \\
\hline $45-49$ & $0.20^{* *}$ & $0.08-0.51$ & 0.46 & $0.15-1.48$ \\
\hline \multicolumn{5}{|l|}{ Parity } \\
\hline One birth & Ref & Ref & Ref & Ref \\
\hline Two births & $0.59^{* *}$ & $0.40-0.87$ & 0.65 & $0.40-1.07$ \\
\hline Three births & $0.52^{* *}$ & $0.35-0.76$ & 0.65 & $0.39-1.09$ \\
\hline Four births or more & $0.31^{* * *}$ & $0.22-0.44$ & 0.70 & $0.41-1.21$ \\
\hline \multicolumn{5}{|l|}{ Partners education } \\
\hline No education & Ref & Ref & Ref & Ref \\
\hline Primary & $2.97^{* * *}$ & $2.15-4.12$ & $1.52^{*}$ & $1.04-2.22$ \\
\hline Secondary & $4.62^{* * *}$ & $3.55-6.01$ & $1.62^{* *}$ & $0.39-1.09$ \\
\hline Higher & $11.50^{* * *}$ & $5.95-22.21$ & 1.65 & $0.41-1.21$ \\
\hline \multicolumn{5}{|c|}{ Distance to health facility } \\
\hline Not a big problem & Ref & Ref & Ref & Ref \\
\hline Big problem & $3.20^{* * *}$ & $2.61-3.93$ & $1.41^{*}$ & $1.06-1.86$ \\
\hline \multicolumn{5}{|c|}{ Money needed for treatment } \\
\hline Not a big problem & Ref & Ref & Ref & Ref \\
\hline Big problem & $2.72^{* * *}$ & $2.21-3.34$ & 1.19 & $0.90-1.58$ \\
\hline \multicolumn{5}{|l|}{ Religion } \\
\hline Christianity & Ref & Ref & Ref & Ref \\
\hline Islam & 0.99 & $0.79-1.23$ & 1.02 & $0.77-1.37$ \\
\hline Traditional/spiritual & $0.12^{* * *}$ & $0.07-0.18$ & $0.26^{* * *}$ & $0.16-0.44$ \\
\hline No religion & $0.18^{* * *}$ & $0.11-0.30$ & $0.37^{* *}$ & $0.20-0.66$ \\
\hline \multicolumn{5}{|l|}{ Residence } \\
\hline Urban & Ref & Ref & Ref & Ref \\
\hline Rural & $0.19^{* * *}$ & $0.14-0.25$ & $0.46^{* * *}$ & $0.31-0.67$ \\
\hline
\end{tabular}

Computed from 2014 GDHS; Ref: reference; ${ }^{*} P<0.05{ }^{* *} P<0.01{ }^{* * *} P<0.001$; model 1 is a bivariate analysis of the individual explanatory variables and the outcome variable; model 2 is a multivariate analysis of all the explanatory variables and the outcome variable. 
among the four regions in the Northern part of Ghana, even though various studies have lumped all four of them together and ascribed the same characteristics for them in relation to sexual and reproductive health which include utilization of skilled delivery services $[24,25]$. The findings where the Northern and Upper West Regions had lower probabilities of utilizing skilled attendance compared to the Brong Ahafo Region may be due to risk perception among women in those regions as the two are known to be poorer regions compared to the latter and lack the basic health facilities [25]. Thus, because women in the two regions are aware of the nonavailability of health facilities in their areas, they do everything they can to access the services in the towns where they are located in time to avoid avoidable deaths which arise from delays in seeking health care [34].

The fact that partner's education predicted delivery even better than the women's own education level points to the significant mediating roles men play in women's health decision-making. This finding is in agreement with studies on influences of partners' characteristics on women's health previous decision-making [35-37]. The implication of this finding is that utilization of skilled delivery services may continue to be low in the Northern parts of the country if male partner involvement is not promoted in the country. This is because societal ascriptions of gender roles for men and women strongly influence access to skilled delivery care for pregnant women [38]. These ascriptions normally make male partners the heads of their respective households. As heads of households, the males mainly decide the means of healthcare accessibility including where the women should seek care [39]. Male partner involvement refers to "the various ways in which men relate to reproductive health problems and programmes, reproductive rights, and reproductive behavior" [40]. Male partner involvement in maternal health care also refers to the direct assistance provided by men to improve their partners' and children's health through the perinatal, antenatal, labor, and delivery period [41].

We also observed that household wealth predicted utilization of skilled delivery. This gives an indication of conceivable significant differences among the respective groupings of the variables. The fact that women who lived in rural residences were less likely to utilize skilled delivery services than urban women is probably due to the fact that the plethora of health facilities are disproportionately located in urban centers. This makes it easier for urban women to utilize such services compared to women who live in rural areas and are largely deprived of such facilities and their accompanied skilled delivery services/skilled birth attendants. This points to various studies which have shown very wide disparities between rural and urban areas with rural areas being the disadvantaged [2, 42].

The fact that most of the background characteristics were found to have predicted utilization of skilled delivery among the women surveyed points to the relevance of Andersen and Newman's [7] proposition that predisposing factors such as age, religion, education, social networks, previous experience with illness, attitudes, and values are significant in informing people's decisions to utilize health care services and facilities.
Despite the important findings made in our study, the limitations inherent in the data and methods used are worth mentioning. Due to the fact that we relied on data which was collected cross-sectionally, we were unable to account for unobserved heterogeneity. Also, the relationships we established between the explanatory and dependent variables may vary over time.

\section{Conclusion}

Our findings which point to the low probability of skilled delivery services utilization among women in the Northern and Upper West Regions call for more attention from the Ghana Health Service, Ministry of Health, and Nongovernmental Organisations (NGOs) involved in maternal and reproductive health issues in addressing the gaps related to the utilization of skilled delivery services among women in those regions. Specifically, efforts should be made to improve the level of education of women on the need for skilled delivery, convince male partners to encourage their spouses to utilize skilled delivery services, and cite more health posts and skilled birth attendants (particularly midwives) in rural areas found in these regions. Ghana's Community-Based Health Planning and Services (CHPS) program which was established in the year 2000 to improve access and quality of healthcare including skilled delivery services throughout the country should also be strengthened in the affected regions. These efforts when implemented would contribute immensely to ensuring the attainment of the Sustainable Development Goal target which requires the country to reduce the maternal mortality ratio to less than 70 maternal deaths per 100,000 live births by the year 2030 .

\section{Conflicts of Interest}

The authors declare that they have no conflicts of interest.

\section{Authors' Contributions}

Kwamena Sekyi Dickson and Hubert Amu conceived the study. Hubert Amu reviewed the relevant literature. Kwamena Sekyi Dickson designed and performed the analysis and methods section. Hubert Amu drafted the manuscript. Both authors proof-read the final manuscript and approved it.

\section{Acknowledgments}

The authors acknowledge MEASURE DHS for granting access to using the DHS data for their analysis.

\section{References}

[1] R. K. Esena and M. M. Sappor, "Factors Associated with the utilization of skilled delivery services in the Ga East Municipality of Ghana Part 2: barriers to skilled delivery," International Journal of Scientific and Technology Research, vol. 2, no. 8, pp. 195-207, 2013. 
[2] World Health Organisation, Global health observatory data: maternal mortality, 2015, http://www.who.int/gho/maternal_ health/mortality/maternal_mortality_text/en/.

[3] Family Care International, "Testing approaches for increasing skilled care during childbirth: the skilled care initiative," Family Care International, New York, NY, USA, 2007.

[4] United Nations Population Fund (UNFPA), Trends in maternal health in Ethiopia: challenges in achieving the MDG for maternal mortality, United Nations Population Fund, Addis Ababa, Ethiopia, 2012.

[5] B. Choulagai, S. Onta, N. Subedi et al., "Barriers to using skilled birth attendants' services in mid- and far-western Nepal: a cross-sectional study," BMC International Health and Human Rights, vol. 13, article 49, 2013.

[6] World Health Organization, Skilled birth attendants, factsheet, World Health Organization, Geneva, Switzerland, 2008.

[7] R. Andersen and J. F. Newman, "Societal and individual determinants of medical care utilization in the United States," Milbank Memorial Fund Quarterly. Health \& Society, vol. 51, no. 1, pp. 95-124, 1973.

[8] R. M. Andersen, "Revisiting the behavioral model and access to medical care: does it matter?" Journal of Health and Social Behavior, vol. 36, no. 1, pp. 1-10, 1995.

[9] R. Andersen and J. F. Newman, "Societal and individual determinants of medical care utilization in the United States," The Milbank Quarterly, vol. 83, no. 4, pp. 1-28, 2005.

[10] A. S. Teferra, F. M. Alemu, and S. M. Woldeyohannes, "Institutional delivery service utilization and associated factors among mothers who gave birth in the last 12 months in Sekela District, North West of Ethiopia: a community-based cross sectional study," BMC Pregnancy and Childbirth, vol. 12, article 74, 2012.

[11] M. Abera, A. Gebremariam, and T. Belachew, "Predictors of safe delivery service utilization in Arsi Zone, South-East Ethiopia," Ethiopian Journal of Health Sciences, vol. 21, no. 1, pp. 95-106, 2011.

[12] E. Lule, G. N. V. Ramana, N. Ooman, J. Epp, D. Huntington, and J. E. Rosen, Achieving the millennium development goal of improving maternal health: determinants, interventions, and challenges, World Bank, Washington, DC, USA, 2005.

[13] S. Onta, B. Choulagai, B. Shrestha, N. Subedi, G. P. Bhandari, and A. Krettek, "Perceptions of users and providers on barriers to utilizing skilled birth care in mid- and far-western Nepal: a qualitative study," Global Health Action, vol. 7, article 24580, 2014.

[14] H. V. Doctor, "Intergenerational differences in antenatal care and supervised deliveries in Nigeria," Health \& Place, vol. 17, no. 2, pp. 480-489, 2011.

[15] M. Amoakoh-Coleman, E. K. Ansah, I. A. Agyepong, D. E. Grobbee, G. A. Kayode, and K. Klipstein-Grobusch, "Predictors of skilled attendance at delivery among antenatal clinic attendants in Ghana: a cross-sectional study of population data," $B M J$ Open, vol. 5, no. 5, Article ID e007810, 2015.

[16] P. M. Lerberg, J. Sundby, A. Jammeh, and A. Fretheim, "Barriers to skilled birth attendance: a survey among mothers in rural Gambia.," African Journal of Reproductive Health, vol. 18, no. 1, pp. 35-43, 2014.

[17] Council for International Development (CID), Sustainable Development Goals: Changing the world in 17 steps - interactive, 2015, http://www.cid.org.nz/news/sustainable-development-goals-changing-the-world-in-17-steps-interactive/.
[18] H. Amu and S. H. Nyarko, "Preparedness of health care professionals in preventing maternal mortality at a public health facility in Ghana: a qualitative study," BMC Health Services Research, vol. 16, article 252, 2016.

[19] United Nations, The Millennium development goals report, United Nations, New York, NY, USA, 2015, http://www.un.org/ millenniumgoals/2015_MDG_Report/pdf/MDG\%202015\%20 rev\%20(July\%201).pdf.

[20] The Guardian, "Sustainable development goals: changing the world in 17 steps - interactive," 2015, http://www.theguardian .com/global-development/ng-interactive/2015/jan/19/sustainable-development-goals-changing-world-17-steps-interactive.

[21] S. K. Mort, "Unveiling the Secrets of the North-South Development Gap of Ghana," 2009, http://www.ghanaweb.com/ GhanaHomePage/features/Unveiling-the-Secrets-of-the-NorthSouth-Development-Gap-of-Ghana-161705.

[22] D. Fusheini, G. Marnoch, and A. M Gray, "The implementation of the National Health Insurance Programme in Ghanaan institutional approach," in Proceedings of the The implementation of the National Health Insurance Programme in Ghanaan institutional approach, pp. 3-5, 2012.

[23] R. K. Alhassan, E. Nketiah-Amponsah, and D. K. Arhinful, "A review of the national health insurance scheme in Ghana: What are the sustainability threats and prospects?" PLoS ONE, vol. 11, no. 11, Article ID e0165151, 2016.

[24] B. O. P. Asamoah, A. Agardh, and E. K. Cromley, "Spatial analysis of skilled birth attendant utilization in Ghana," Global Journal of Health Science, vol. 6, no. 4, pp. 117-127, 2014.

[25] S. K. Annim, S. Mariwah, and J. Sebu, "Spatial inequality and household poverty in Ghana," Economic Systems, vol. 36, no. 4, pp. 487-505, 2012.

[26] D. K. Ofosu, Assessing the spatial distribution of health facilities in the Eastern Region of Ghana, Kwame Nkrumah University of Science and Technology, Kumasi, Ghana, 2012.

[27] J. Heyen-Perschon, Report on current situation in the health sector of Ghana and possible roles for appropriate transport technology and transport related communication interventions, Institute for Transportation and Development Policy, New York, NY, USA, 2005.

[28] P. A. Abor, G. Abekah-Nkrumah, K. Sakyi, C. K. D. Adjasi, and J. Abor, "The socio-economic determinants of maternal health care utilization in Ghana," International Journal of Social Economics, vol. 38, no. 7, pp. 628-648, 2011.

[29] I. Addai, "Determinants of use of maternal-child health services in rural Ghana," Journal of Biosocial Science, vol. 32, no. 1, pp. 1$15,2000$.

[30] I. Addai, "Demographic and sociocultural factors influencing use of maternal health services in Ghana.," African Journal of Reproductive Health, vol. 2, no. 1, pp. 73-80, 1998.

[31] D. Buor, "Determinants of utilisation of health services by women in rural and urban areas in Ghana," GeoJournal, vol. 61, no. 1, pp. 89-102, 2004.

[32] G. B. Fosu, "Childhood morbidity and health services utilization: Cross-national comparisons of user-related factors from DHS data," Social Science \& Medicine, vol. 38, no. 9, pp. 12091220, 1994.

[33] "Ghana Statistical Service (GSS), Ghana Health Service (GHS), ICF International, Ghana demographic and health survey 2014, Maryland, United States, 2015”.

[34] S. Thaddeus and D. Maine, "Too far to walk: Maternal mortality in context," Social Science \& Medicine, vol. 38, no. 8, pp. 10911110, 1994. 
[35] K. S. Dickson, E. K. M. Darteh, and A. Kumi-Kyereme, "Providers of antenatal care services in Ghana: Evidence from Ghana demographic and health surveys 1988-2014," BMC Health Services Research, vol. 17, no. 203, pp. 1-9, 2017.

[36] A. Kumi-Kyereme and J. Amo-Adjei, "Effects of spatial location and household wealth on health insurance subscription among women in Ghana," BMC Health Services Research, vol. 13, no. 221, 2013.

[37] L. A. Rempel and J. K. Rempel, "Partner influence on health behavior decision-making: Increasing breastfeeding duration," Journal of Social and Personal Relationships, vol. 21, no. 1, pp. 92-111, 2004.

[38] T. Ensor and S. Cooper, "Overcoming barriers to health service access: Influencing the demand side," Health Policy and Planning, vol. 19, no. 2, pp. 69-79, 2004.

[39] H. Amu and K. S. Dickson, "Health insurance subscription among women in reproductive age in Ghana: do sociodemographics matter?" Health Economics Review (HER), vol. 6, article 24, 2016.

[40] A. Kumar, "Role of males in reproductive and sexual health decisions," The Bihar Times, 2007, http://www.bihartimes.com/ articles/anant/roleofmales.htm.

[41] F. Ampt, M. M. Mon, K. K. Than et al., "Correlates of male involvement in maternal and newborn health: a cross-sectional study of men in a peri-urban region of Myanmar," BMC Pregnancy and Childbirth, vol. 15, p. 122, 2015.

[42] M. Alemayehu and W. Mekonnen, "The prevalence of skilled birth attendant utilization and its correlates in North West Ethiopia," BioMed Research International, vol. 2015, Article ID 436938, 8 pages, 2015. 


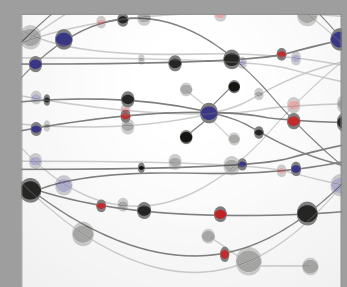

The Scientific World Journal
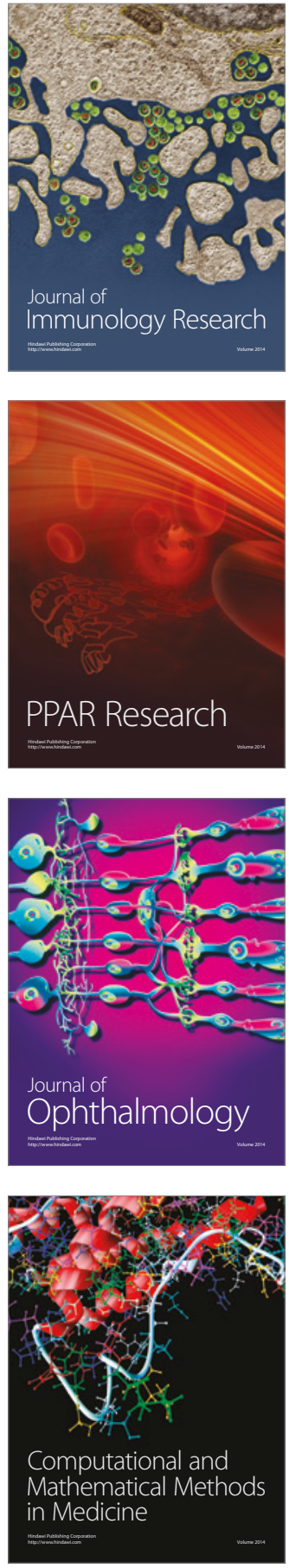

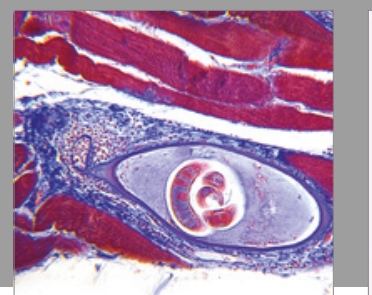

Gastroenterology Research and Practice
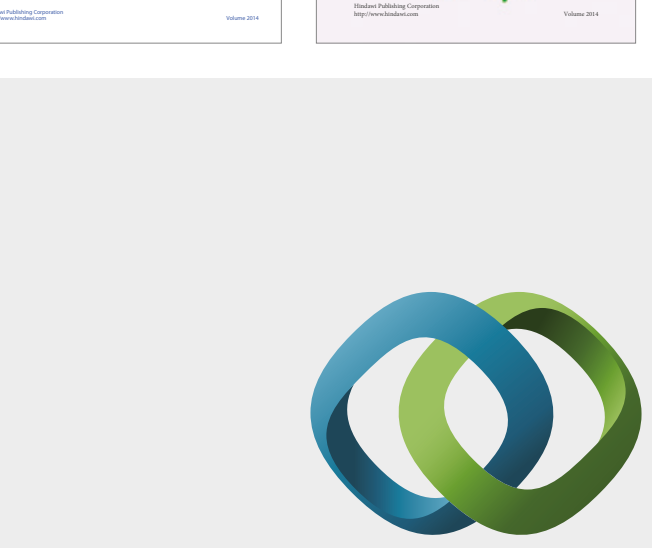

\section{Hindawi}

Submit your manuscripts at

https://www.hindawi.com
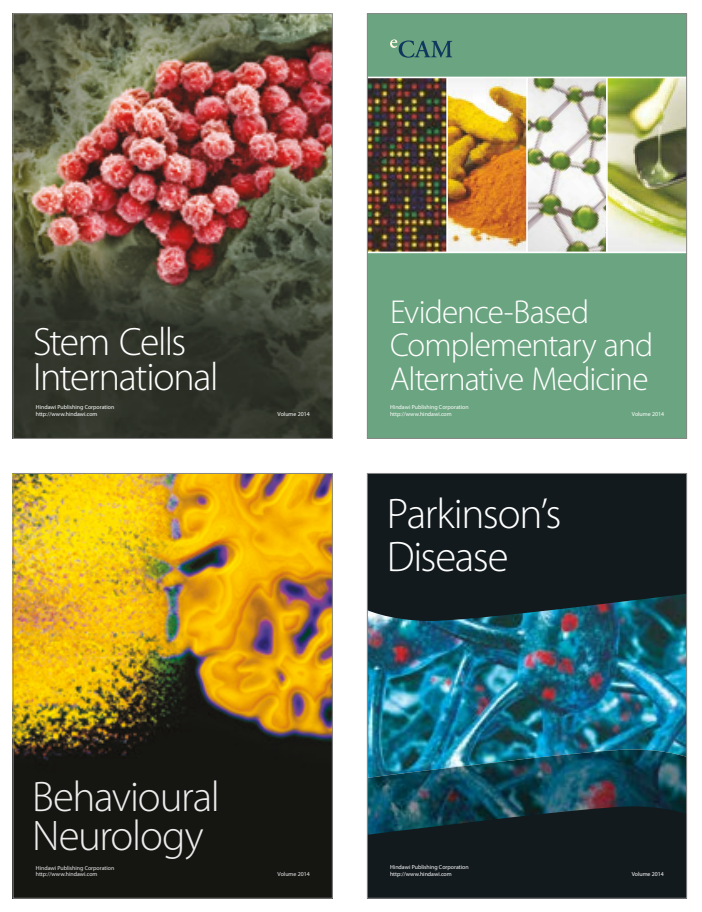
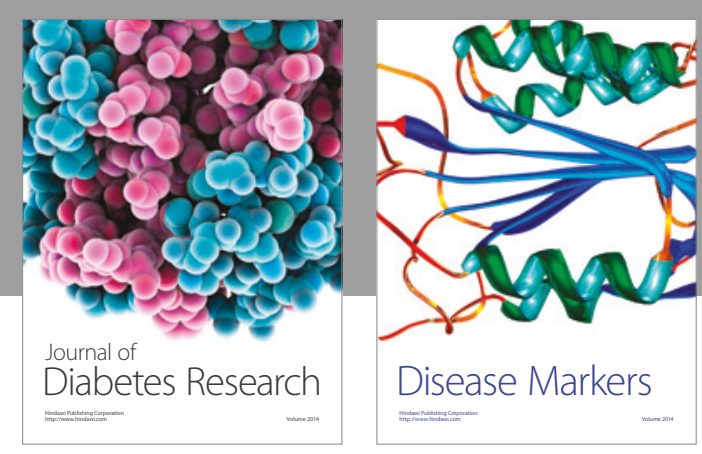

Disease Markers
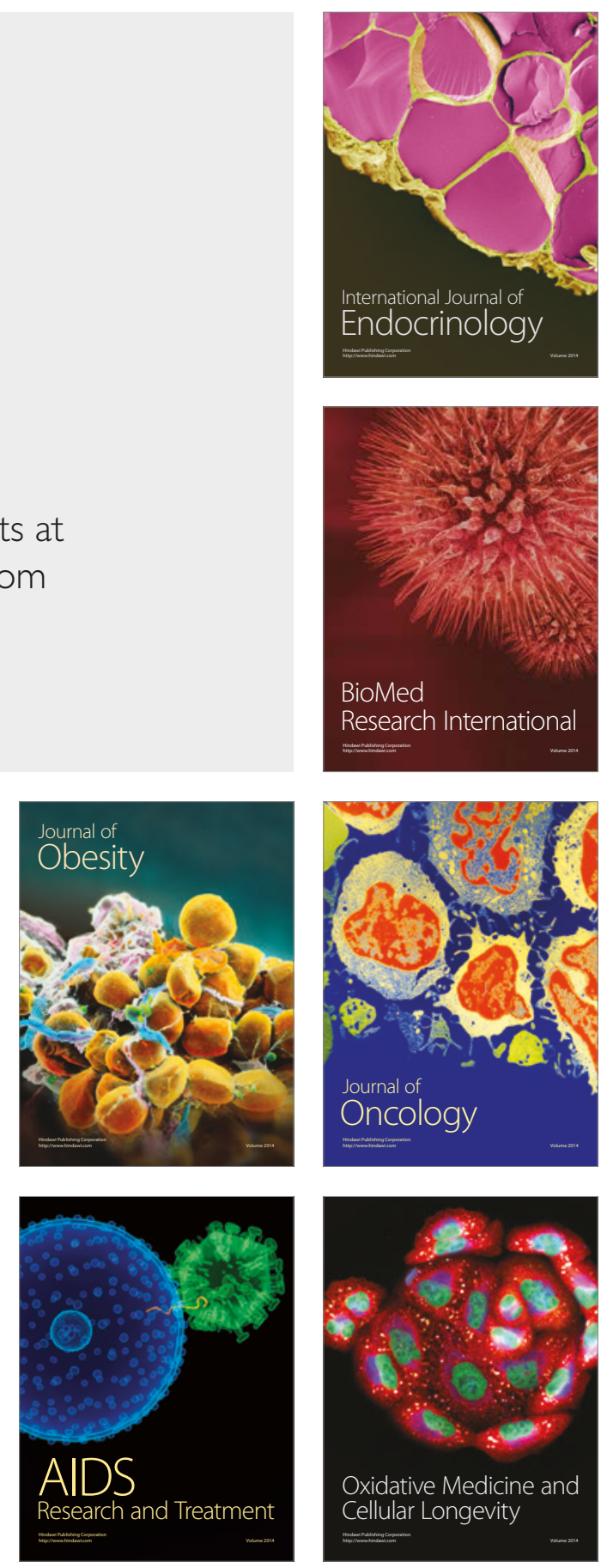